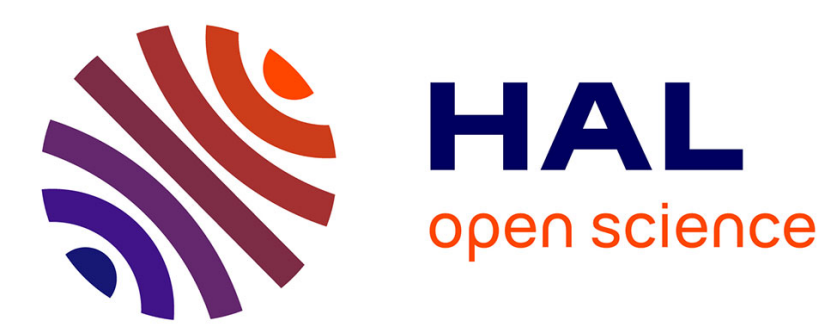

\title{
Can cat predation help competitors coexist in seabird communities?
}

\author{
Dominique Pontier, David Fouchet, J. Joël Bried
}

\section{To cite this version:}

Dominique Pontier, David Fouchet, J. Joël Bried. Can cat predation help competitors coexist in seabird communities?. Journal of Theoretical Biology, 2009, 262 (1), pp.90. 10.1016/j.jtbi.2009.09.006 . hal-00559157

\section{HAL Id: hal-00559157 \\ https://hal.science/hal-00559157}

Submitted on 25 Jan 2011

HAL is a multi-disciplinary open access archive for the deposit and dissemination of scientific research documents, whether they are published or not. The documents may come from teaching and research institutions in France or abroad, or from public or private research centers.
L'archive ouverte pluridisciplinaire HAL, est destinée au dépôt et à la diffusion de documents scientifiques de niveau recherche, publiés ou non, émanant des établissements d'enseignement et de recherche français ou étrangers, des laboratoires publics ou privés. 


\section{Author's Accepted Manuscript}

Can cat predation help competitors coexist in seabird communities?

Dominique Pontier, David Fouchet, Joël Bried

PII:

S0022-5193(09)00426-3

DOI: doi:10.1016/j.jtbi.2009.09.006

Reference: YJTBI 5697

To appear in:

Journal of Theoretical Biology

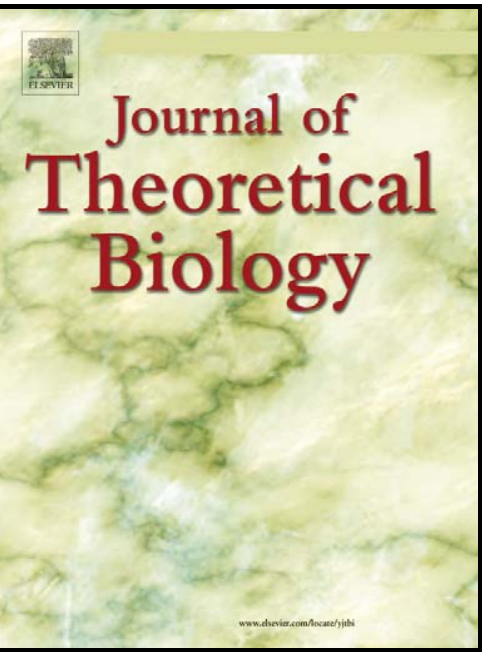

www.elsevier.com/locate/yjtb

Received date: 2 March 2009

Revised date: 22 August 2009

Accepted date: $\quad 6$ September 2009

Cite this article as: Dominique Pontier, David Fouchet and Joël Bried, Can cat predation help competitors coexist in seabird communities?, Journal of Theoretical Biology, doi:10.1016/j.jtbi.2009.09.006

This is a PDF file of an unedited manuscript that has been accepted for publication. As a service to our customers we are providing this early version of the manuscript. The manuscript will undergo copyediting, typesetting, and review of the resulting galley proof before it is published in its final citable form. Please note that during the production process errors may be discovered which could affect the content, and all legal disclaimers that apply to the journal pertain. 


\title{
Can cat predation help competitors coexist in seabird
}

\section{communities?}

\author{
Dominique Pontier $^{\mathrm{a}, *}$, David Fouchet ${ }^{\mathrm{a}}$, Joël Bried ${ }^{\mathrm{b}}$ \\ ${ }^{a}$ Université de Lyon, F-69000, Lyon, Université Lyon1, CNRS, UMR5558, Laboratoire de Biométrie et Biologie \\ Evolutive, F-69622 69622, Villeurbanne, France. \\ ${ }^{b}$ Departamento de Oceanografia e Pescas, Centro do IMAR da Universidade dos Açores, 9901-862 Horta, \\ Açores, Portugal. \\ * Corresponding author at: Université de Lyon, F-69000, Lyon, Université Lyon1, CNRS, UMR5558, \\ Laboratoire de Biométrie et Biologie Evolutive, F-69622 69622, Villeurbanne, France. Tel.: +33 47243 13 37; \\ fax: +33472431388 \\ Email addresses: dpontier@biomserv.univ-lyon1.fr (D. Pontier), fouchet@biomserv.univ-lyon1.fr (D. Fouchet), \\ joelbried@yahoo.com or jbried@uac.pt (J. Bried).
}

Main text: 4128 words

Summary: 264 words

Number of references: 60

Running title: Early breeding in seabirds that compete for nests and against predators 


\section{ABSTRACT}

On oceanic islands, nest site availability can be an important factor regulating seabird population dynamics. The potential for birds to secure a nest to reproduce can be an important component of their life histories. The dates at which different seabird species arrive at colonies to breed will have important consequences for their relative chances of success. Early arrival on the island allows birds to obtain nests more easily and have higher reproductive success. However, the presence of an introduced predator may reverse this situation. For instance, in the sub-Antarctic Kerguelen archipelago, early-arriving birds suffer heavy predation from introduced cats. Cats progressively switch from seabirds to rabbits, since the local rabbit population starts to peak after early-arriving seabird species have already returned to the colony. When late-arriving birds arrive, cat predation pressure on seabirds is thus weaker. In this paper, we investigate the assumption that the advantage of early nest monopolization conferred to early-arriving birds may be counterbalanced by the cost resulting from predation. We develop a mathematical model representing a simplified situation in which two insular seabird species differ only in their arrival date at the colony site and compete for nesting sites. We conclude that predation may ensure the coexistence of the two bird species or favor the late-arriving species, but only when seasonal variations in predation pressure are large. Interestingly, we conclude that arriving early is only favorable until a given level where high reproductive success no longer compensates for the long exposure to strong predation pressure. Our work suggests that predation can help maintain the balance between species of different phenologies.

Keywords: oceanic islands, seabirds, feral cats, nest site availability, date of arrival, community structure, predator-prey relationships, model 


\section{Introduction}

Nests are fundamental resources for many species. In seasonally breeding species, competition for nesting sites may depend on the date at which individuals arrive at the site, with early-arriving individuals theoretically able to secure higher quality territories than laterarriving ones (Pulliam and Danielson, 1991; Kokko, 1999). Several studies on different taxa that face strong competition for breeding territories - including insects (e.g., Wang et al., 1990), birds (e.g., Rowan, 1965; Greenwood and Harvey, 1982) and mammals (Bried et al., 2009) - have supported this hypothesis. Such competition can be inter-species (e.g., Quintana and Yorio, 1998), intra-species (e.g., Rowan, 1965; Candolin and Voigt, 2001), or both intraand inter-species (e.g., Ramos et al., 1997).

In seasonal seabirds, the date of arrival at the breeding grounds and the laying date tend to vary among species due to exogenous (photoperiod) and endogenous factors (e.g., individual hormonal status, circadian rhythm) that elicit migratory and breeding behavior, and/or to differences in feeding ecology (Both and Visser, 2001; Le Corre, 2001; Brooke, 2004; Lehikoinen et al., 2004). Early breeding is generally advantageous in terms of breeding success (Nelson, 1980; Daan et al., 1988; see also Ollason and Dunnet, 1988; Barba et al., 1995; Sydeman and Eddy, 1995). However, if the breeding locality harbors a predatory species that faces a food shortage during the period when birds are absent, the earliest-arriving individuals are also the most likely to suffer mortality due to predation. The critical question here is: can predation counterbalance the cost of arriving later at the breeding grounds?

To address this question, insular seabird species represent especially suitable models. On most oceanic islands, seabirds have evolved without terrestrial mammalian predators until recently, when rats (Rattus spp.) and cats (Felis silvestris catus) were introduced by humans on several islands (Atkinson, 1985; Johnstone, 1985; Veitch, 1985). Many seabird species lack the behavioral and ecological adaptations that would enable them to cope successfully 
with mammalian predators (Lack, 1968; Warham, 1990). Consequently, the impact of introduced predators on insular seabird populations has been catastrophic in most cases (Atkinson, 1985; Veitch, 1985; Pontier et al., 2002; Blackburn et al., 2000).

Pontier et al. (2008) studied certain aspects of competition for nesting sites in a seabird species that faces predation from cats. They concluded that, surprisingly, limited nest site availability could favor the long-term persistence of the seabird population by creating a large pool of non-breeding birds that can buffer the demographic impacts of factors such as bad climatic conditions on land. However, their model was a predator-prey model that included only one prey species and prey breeding limitation. The potential existence of several species competing for nest sites was neglected. The present paper aims to determine whether and how the outcome of this competition is affected by predation.

There are several mechanisms through which predators can alter the strength and direction of competition between prey species (Chase et al., 2002). It is widely acknowledged that alien predators are a major factor in biodiversity loss (Courchamp et al., 2003). Indeed, the first direct effect of predation is a reduced abundance of native prey and hence an increased risk of extinction. Moreover, predation can generate indirect competition between two otherwise independent prey species, which can potentially lead to the extinction of one of the two prey species (Courchamp et al., 1999). This is because increasing the abundance of one prey species leads to an increase in predator numbers and hence a decline in the other prey population. However, some mechanisms may allow predation to promote coexistence between prey species. This is the case, for example, if prey that are the best competitors for resources are the most vulnerable to predation (Armstrong, 1979; Abrams, 1999; Leibold, 1996), when different prey species occupy different shelters to avoid predation (Jeffries and Lawton, 1984; Holt and Lawton, 1994) or when the intensity of predation depends on prey density (Roughgarden and Feldman, 1975; Gendron, 1987; Huntly, 1991). 
To investigate how predation by introduced cats (hereafter referred to as predation) can modify the benefit-cost balance of arriving early at the nesting sites and hence alter seabird community structure, we built a mathematical model considering two seabird species that differ only in their date of arrival on a hypothetical remote island. These species both face predation and share the same nesting sites. One fundamental model assumption is that the impact of cat predation may differ between seabird species according to their date of arrival. Indeed, early-arriving birds arrive before a surge in the rabbit population and therefore constitute the main prey of cats during this period. Late-arriving birds suffer weaker predation because they return to the island at the moment when rabbits become abundant and are again an important target for cats. Here we determine whether predation can help late-arriving birds - which here are always disadvantaged in the absence of predation - to obtain nest sites and to breed as successfully as their early-arriving counterparts.

\section{Materials and methods}

\subsection{The mathematical model}

Our mathematical model extends classical Lotka-Volterra Competition equations (see Murray, 2003, for a review). It is parameterized to represent two typical colonial burrownesting seabird species on an island (or a group of islands) that is home to both cats and rabbits, as in the Kerguelen archipelago, southern Indian ocean (Pontier et al., 2002), or on the Canary Islands, subtropical north-eastern Atlantic (Nogales and Medina, 2009). The first species of birds breeds early (early breeders, species 1), while the second species starts breeding later (late breeders, species 2). In our model, superscript labels 1 and 2 represent early and late breeders, respectively. The two seabird species are assumed to be otherwise identical. Given this framework, we can be sure that the outcome of the competition between 
the two seabird species will be the result of the selective advantage and disadvantage conferred by their dates of arrival on the island.

Our model is a simplified version of that proposed by Pontier et al. (2008). We consider two seabird species with a balanced sex ratio, such that the model only represents the changes in the number of females. The birds' life cycle is illustrated in Figure 1 . We use $K_{n}$ to denote the number of available nesting sites on the island, with $B_{n}(t)$ being the number of nests occupied at time $t$. To simplify, we assume that all the birds occupying a nest behave in the same manner: all birds leave the colony at the same time at the end of the breeding season, and if one individual in a nest dies, then all the individuals from this nest will die. Given the extended incubation period in seabirds (between 18 and 83 days, depending on the species; see Appendix 2 in Schreiber and Burger, 2002), the bulk of predation occurs before the eggs hatch (especially in the early-arriving species) and hence mainly affects adults. This pattern results in a very high rate of breeding failure: without biparental care, chicks die along with their parents (see Lack, 1968).

At time $t_{1}\left(t_{2}\right)$, all the individuals of species 1 (species 2) leave the nest, leading to a number $b B_{n}{ }^{l}\left(b B_{n}{ }^{2}\right)$ of immature individuals, where $b$ is the average number of juveniles in each occupied nest. The 'immature' class $\left(B_{i}\right)$ includes all individuals between fledging and the age when they will become socially mature (compartment $B_{m}$ ) at a rate $\gamma_{1}$. All the birds that have returned to the colony at least once since fledging and the birds that will return ashore for the first time in their lives during the current breeding season are considered 'socially mature'. Socially mature birds become prospectors at a rate $\gamma_{2}^{l}(t)$ for early breeders and $\gamma_{2}^{2}(t)$ for late breeders. Prospectors (class $B_{p}$ ) are those individuals that come ashore during the current breeding season. This class includes both former breeders that are ready to breed again and individuals that are now ready to breed for the first time. During the appropriate period of the year that depends on seabird species (the seasonal behavior of the 
two seabird species as modeled here is represented in Figure 2), prospecting birds start colonizing vacant nests (at a rate $\mu^{l}(t)$ for early breeders and $\mu^{2}(t)$ for late breeders). All the birds face a natural mortality (i.e., mortality due to any cause other than predation) at rate $m$.

We introduce a saturating term to model the rate at which socially mature birds become prospectors: we assume that the number of breeding and prospecting birds is limited to a certain quantity, $K_{b}$, due to limited resources at sea. Indeed, the distribution and abundance of marine organisms (Waluda et al., 1999), linked to variations in oceanographic conditions (e.g., Deacon, 1977), can directly influence individuals' body reserves, their breeding performance, their age at sexual maturity, adult survival rates, colony attendance and the proportion of breeding adults (Drent and Daan, 1980; Erikstad et al., 1998; Weimerskirch, 2002; Inchausti et al., 2003; Sandvik and Erikstad, 2008).

Our main simplification is that we do not model the dynamics of the cat population explicitly. This is a justifiable simplification since here we investigate how a varying (timedependent) predation pressure will influence the outcome of the competition between bird species. Not considering the dynamics of cats explicitly offers two advantages. First, we can easily control the time-dependence of the level of predation exerted on birds - much more easily than when predation pressure arises from complex dynamic interactions between birds, cats and their alternative preys. Second, it allows for easy extensions of the model. Here, predation is simply represented by a time-dependent increase in the mortality rate of nesting birds. It can easily be replaced by any factor that causes time-dependent additional mortality for nesting birds. For example, the conclusions of the model can be extended to situations where a seasonal disease would only affect nesting birds.

To simplify, the time-dependent mortality rate due to predation is chosen independent of the number of birds in the population. Only the birds occupying nests suffer predation. $P(t)$ 
denotes the time-dependent mortality rate of birds as a result of predation, i.e., the rate at which occupied nests become vacant due to predation.

The model reads:

If $t \neq t_{1}$ :

$$
\begin{aligned}
& \frac{d B_{i}^{1}}{d t}=-\left[\gamma_{1}+m\right] B_{i}^{1} \\
& \frac{d B_{m}^{1}}{d t}=\gamma_{1} B_{i}^{1}-\gamma_{2}^{1}(t)\left[1-\frac{\left.B_{p}^{1}+B_{n}^{1}+B_{p}^{2}+B_{n}^{2}\right]}{K_{b}}\right] B_{m}^{1}-m B_{m}^{1} \\
& \frac{d B_{p}^{1}}{d t}=\gamma_{2}^{1}(t)\left[1-\frac{B_{p}^{1}+B_{n}^{1}+B_{p}^{2}+B_{n}^{2}}{K_{b}}\right] B_{m}^{1}-m B_{p}^{1}-\mu^{1}(t)\left[1-\frac{B_{n}^{1}+B_{n}^{2}}{K_{n}}\right] B_{p}^{1} \\
& \frac{d B_{n}^{1}}{d t}=\mu^{1}(t)\left[1-\frac{B_{n}^{1}+B_{n}^{2}}{K_{n}}\right] B_{p}^{1}-[m+P(t)] B_{n}^{1}
\end{aligned}
$$

and if $t \neq t_{2}$ :

$$
\begin{aligned}
& \frac{d B_{i}^{2}}{d t}=-\left[\gamma_{1}+m\right] B_{i}^{2} \\
& \frac{d B_{m}^{2}}{d t}=\gamma_{1} B_{i}^{2}-\gamma_{2}^{2}(t)\left[1-\frac{\left.B_{p}^{1}+B_{n}^{1}+B_{p}^{2}+B_{n}^{2}\right]}{K_{b}}\right] B_{m}^{2}-m B_{m}^{2} \\
& \frac{d B_{p}^{2}}{d t}=\gamma_{2}^{2}(t)\left[1-\frac{B_{p}^{1}+B_{n}^{1}+B_{p}^{2}+B_{n}^{2}}{K_{b}}\right] B_{m}^{2}-m B_{p}^{2}-\mu^{2}(t)\left[1-\frac{B_{n}^{1}+B_{n}^{2}}{K_{n}}\right] B_{p}^{2} \\
& \frac{d B_{n}^{2}}{d t}=\mu^{2}(t)\left[1-\frac{B_{n}^{1}+B_{n}^{2}}{K_{n}}\right] B_{p}^{2}-[m+P(t)] B_{n}^{2}
\end{aligned}
$$

Since all the breeding birds and juveniles of each bird species leave the island at the same time at the end of the breeding season (at $t=t_{1}$ for early breeders and $t=t_{2}$ for late breeders; breeding adults return to the 'socially mature' class), we also have the following constraints:

$$
\begin{aligned}
& B_{i}^{1}\left(t_{1}^{+}\right)=B_{i}^{1}\left(t_{1}^{-}\right)+b B_{n}^{1}\left(t_{1}^{-}\right) \\
& B_{m}^{1}\left(t_{1}^{+}\right)=B_{m}^{1}\left(t_{1}^{-}\right)+B_{n}^{1}\left(t_{1}^{-}\right)
\end{aligned}
$$




$$
\begin{aligned}
& B_{n}^{1}\left(t_{1}^{+}\right)=0 \\
& B_{i}^{2}\left(t_{2}^{+}\right)=B_{i}^{2}\left(t_{2}^{-}\right)+b B_{n}^{2}\left(t_{2}^{-}\right) \\
& B_{p}^{2}\left(t_{2}^{+}\right)=B_{p}^{2}\left(t_{2}^{-}\right)+B_{n}^{2}\left(t_{2}^{-}\right) \\
& B_{n}^{2}\left(t_{1}^{+}\right)=0
\end{aligned}
$$

\subsection{Model parameters}

The model time unit is the year. Whenever possible, we use basic values consistent with the parameters proposed by Pontier et al. (2008). The rate at which birds become socially mature is $\gamma_{l}=0.25$ year $^{-1}$. The maximum number of birds in breeding condition $\left(K_{b}\right)$, that is, physiologically able to breed, is chosen equal to $10^{5}$ birds, and we assume that there are $10^{4}$ nesting sites on the island. Bird hatching and mortality rates are $b=0.5$ and $m=0.09$ year $^{-1}$, corresponding to an annual adult survival rate of $e^{-0.09}=0.91$.

Here seasonal rates are modeled as step functions (see also Figure 2):

$$
\begin{aligned}
& P(t)= \begin{cases}\rho & \text { if } t_{2}+0.5<\mathrm{t}<t_{1}+\Delta_{\mathrm{p}}+0.5 \\
\rho \varepsilon & \text { if } t_{1}+\Delta_{\mathrm{p}}+0.5<\mathrm{t}<1 \text { or } 0<\mathrm{t}<t_{1} \\
0 & \text { else }\end{cases} \\
& \gamma_{2}^{1}(t)= \begin{cases}\gamma_{0} & \text { if } t_{1}<\mathrm{t}<t_{1}+0.5 \\
0 & \text { else }\end{cases} \\
& \gamma_{2}^{2}(t)= \begin{cases}\gamma_{0} & \text { if } t_{2}<\mathrm{t}<t_{2}+0.5 \\
0 & \text { else }\end{cases} \\
& \mu^{1}(t)= \begin{cases}\mu_{0} & \text { if } t_{1}+0.5<\mathrm{t}<t_{1}+7 / 12 \\
0 & \text { else }\end{cases} \\
& \mu^{2}(t)= \begin{cases}\mu_{0} & \text { if } t_{2}+0.5<\mathrm{t}<t_{2}+7 / 12 \\
0 & \text { else }\end{cases}
\end{aligned}
$$


The phenology of late breeders is chosen as a reference. The time elapsed between the arrival on land of early breeders and that of late breeders is given by $\Delta_{B}$, i.e., the time during which species 1 suffers strong predation alone. During the strong predation phase, the mortality induced by predation involving the birds that occupy nests is $P(t)=\rho$ and during the weak predation phase it is $P(t)=\rho \varepsilon$. The time lag between the arrival of the late breeders ashore and the end of the phase of strong predation is represented by $\Delta_{P}=t_{2}-t_{1} . \varepsilon$ represents the ratio between the predation-induced mortality during the weak predation phase and that associated with the strong predation phase. Note that the impact of these parameters is often tested and hence they have no basic value. Values of $\mu_{0}$ and $\gamma_{0}$ are assumed to have mean temporal values equal to those suggested by Pontier et al. (2008), leading to $\mu_{0}=76.39$ year $^{-1}$ and $\gamma_{0}=12.73$ year $^{-1}$. Finally, the basic values for the time lags are set to $\Delta_{B}=1$ month and $\Delta_{P}=0$, so that only late breeders occupy nests during the strong predation pressure period.

\section{Results}

\subsection{Competition between seabird species without predation}

First, we perform a quick analysis of the model where the predation term is set to 0 - i.e., $\rho=0$. We focus on competition between the two bird species (for the effect of the number of nests on the distribution of birds within classes, see Pontier et al., 2008).

The two species differ only in their breeding phenology. As a consequence, without predation and with all else being equal, the demographic trends of each species will be directly related to its reproductive success. Given this fact, early arrival permits early breeders to monopolize nests, affording them an important evolutionary advantage over their competitors. In other words, the competition is always won by the early breeders. Figure 3 illustrates the general behavior of the system: whatever the initial conditions, late breeders go extinct while early breeders thrive. 


\subsection{Effect of predation on inter-species competition for nests}

Since predation is most severe at the time when early breeders arrive at the colony, early breeders experience increased mortality. This results in an increasing number of vacant nests, which may then be available to late breeders. Do increased mortality and the turn-over in nests induced by predation balance the selective advantage of nest monopolization conferred by early breeding?

Our results show that the response to this problem depends on many factors, mainly the predation pressure. Unsurprisingly, under weak predation pressures, early breeders are always favored (Figure $4 \mathrm{a}, \rho=0.5$ ). Strong predation pressures tend to favor late breeders (Figure $4 \mathrm{~b}$, $\rho=1.5$ ), but if predation is too strong both species go extinct (Figure $4 \mathrm{c}, \rho=3$ ). Asymptotic coexistence, where the two species coexist in a stable cyclic state, is apparent in our model but only for restricted ranges of the parameters. Temporary coexistence (Figure $4 \mathrm{~d}, \rho=1$ ) i.e., coexistence during an ecologically long period of time (up to several hundred years) - is apparent for a broader range of values.

To assess the importance of the model parameters in terms of the outcome of the competition between the two bird species, we define four regimes in which the system can fall. To do this, we start from an initial state where early breeders are at the predation-free equilibrium and the number of birds in each class of the model in late breeders is equal to $1 \%$ of the number of birds in the same class in early breeders. We consider a species to be persistent at the ecological scale when its total numbers after 200 years are at least equal to the initial (i.e., time 0 ) total number of late breeders. This gives a good idea of the outcome of the competition between the two seabird species at an ecological scale.

We define the 'late breeders' and 'early breeders' regimes as being those in which only late breeders or only early breeders, respectively, persist after 200 years. We define as the 
'coexistence' regime the situation for which both seabird species are persistent after 200 years. We define as the 'extinction' regime the regime under which both species have disappeared after 200 years.

First, we consider the basic values of the parameters and determine the impact of the maximum predation pressure $(\rho)$ and the relative predation pressure between the weak and strong predation periods $(\varepsilon)$. Since $\Delta_{p}=0$, late breeders do not suffer any predation when $\varepsilon=0$. They are favored when the predation pressure - exerted only on their competitors - is strong (Figure 5a). Under lower predation pressures, the two seabird species coexist, but only for a restricted range of $\rho$. The selective advantage of late breeders rapidly decreases as $\varepsilon$ increases. Although strong predation levels are required to balance the selective advantage conferred by early breeding, for $\varepsilon>0.45$ even late breeders cannot cope with the predation-induced mortality. In other words, seasonal variations in predation pressure must be significant to generate an environment where late breeders coexist with early breeders or are favored.

Next we investigate the effect of the other nine parameters. Here we only present the results obtained for the time lag between the arrival of the two species at the colony site $\left(\Delta_{B}\right)$ and between the arrival of late breeders and the end of the strong predation phase $\left(\Delta_{P}\right)$, which are the most important for the outcome of the competition. Results obtained using the seven remaining parameters are presented in the electronic supplementary material. To determine realistic time lag values that are compatible with the coexistence of both species or with a reverse outcome of the competition between the two bird species, we need to understand how the main model parameters impact competition. Therefore, we set $\varepsilon=0.1$, a value that allows both coexistence, selection of early or late breeders and the extinction of both species, depending on the value of $\rho$ (Figure 5a). $\rho$ is variable in all figures.

The most important factor in terms of the persistence of late breeders - alone or coexisting with early breeders - is the time lag between the arrival at the colony of the two bird species 
$\left(\Delta_{B}\right)$ (Figure $\left.5 \mathrm{~b}\right)$. Short time lags clearly favor early breeders, which have time to colonize a large number of nests without being at significant risk of predation. As a result, late breeders cannot persist when the time lag is shorter than one week. Above this threshold, we can see that as the time lag increases, the long-term persistence of late breeders is apparent for a broader range of values of $\rho$. This is because arriving earlier does not give early breeders a greater chance to breed, but it rather exposes them to longer sustained predation pressure. In that sense, increasing $\Delta_{B}$ is similar to increasing $\varepsilon$ while keeping $\rho \varepsilon$ constant.

Figure $5 \mathrm{c}$ shows that short predation time lags $\left(\Delta_{P}\right)$ favor the long-term persistence of late breeders. This can be explained by the fact that if the intense predation phase lasts over a long period when late breeders are nesting, then the differential in the predation pressure suffered by the two species will tend to be minimized. Moreover, longer time lags lead to all of the birds being more strongly affected by predation and this in turn will decrease the value of the predation coefficient $(\rho)$, above which both species may go extinct.

\section{Discussion}

Studying the impact of introduced predators is of great importance for the conservation of seabirds on sub-Antarctic, tropical and temperate islands where the native avifauna exhibits high levels of endemism and trophic webs are simplified. However, the problem of seabird population management cannot be regarded as a simple prey-predator interaction, where decreasing predator population size would lead to a straightforward growth in the prey population. For example, theoretical (Courchamp et al., 1999) and empirical (Palomares and Caro, 1999) evidence have shown that removing a top predator can lead to an increase in a mesopredator population and, surprisingly, to an eventual decrease in the prey population when the mesopredator also preys on the prey (a phenomenon known as the "mesopredator release effect'). In such a context, models represent useful tools that can offer important 
insights into the mechanisms involved (Courchamp et al., 2000; Gaucel et al., 2005; Gaucel and Pontier, 2005; Zhang et al., 2006).

Here we determine whether and how the presence of a predator, combined with competition for nesting sites, may affect the seabird community structure, either by favoring long-term coexistence between late- and early-arriving seabird species or by reversing the outcome of competition by favoring late breeders. Considering two species that differ only in terms of their date of arrival on the island, we showed that, in the absence of a top predator, competition for nests ends up pushing the later-arriving species to extinction. Such a situation might occur in the near future with, for example, the Bulwer's petrels Bulweria bulwerii from the Azores (northern subtropical Atlantic), which face strong competition for burrows with the larger Cory's shearwaters Calonectris diomedea (Ramos et al., 1997; Bried and Bourgeois, 2005).

The presence of cats alters the outcome of competition between the two species, provided that the predation pressure faced by nesting seabirds exhibits large seasonal variations. The over-predation suffered by the early-arriving birds counterbalances (and sometimes offsets) the benefits of their early nest monopolization. As a result, this permits coexistence between the two bird species or even the competitive exclusion of early-arriving birds. To test model predictions, it would be interesting to compare the relative distribution of species having different dates of arrival in areas with and without cat predation. The Kerguelen archipelago is especially suitable for studying this question, since it includes islands with and without cats. However, it is obvious that the model presented here is more general and may be equally valid for seabird species that breed on other oceanic islands where mammalian predators have been introduced.

One fundamental model parameter is the magnitude of seasonal fluctuations in cat predation pressure. Even though early-arriving birds suffer from stronger predation than late- 
arriving ones, strong predation only occurs during a short period, and strong predation pressure is essential to counterbalance the huge advantage conferred by early nest monopolization. However, if this pressure is also strong for late-arriving birds, both species will go extinct. As a result, the long-term persistence of late-arriving birds is apparent only when the differential in predation pressure is very large. It is also interesting to note that the optimal date of arrival for one species depends on the strategy adopted by the other. Arriving at a time $t$ can be advantageous when the other species arrive at time $t+\varepsilon$, but disadvantageous when other individuals arrive at time $t+2 \varepsilon$. This is because a small differential in the date of arrival is sufficient to monopolize nesting sites. A larger differential mainly leads to a longer period of strong predation without providing important advantages for reproduction.

Considering the effects of other model parameters as well as the values of the parameters chosen (the latter were favored considering the seabird populations from the Kerguelen archipelago), we estimate that the ratio of predation pressures between the strong and weak predation phases must be at least $1 / \varepsilon=2$ to ensure the long-term persistence of late-arriving birds. It is challenging to determine whether this is realistic in the field, but considering that rabbit densities can become extremely high in summer, a differential of 2 in the pressure between high and low predation phases seems plausible.

Our model, of course, simplifies a complex system. Several aspects of the system have been neglected to make the model more readable. In particular, we assumed that the two seabird species behaved identically except for their arrival date at the colony. The date at which seabird species come ashore to breed is conditioned by the phenology of their prey (see Introduction). A species arriving at a given date one year may arrive slightly earlier or later the next year. Furthermore, species are never strictly identical, and other fitness constraints (such as physiological constraints) may result in additional costs related to early breeding. All of these factors, not modeled here, may explain why early- and late-arriving species can 
coexist within the same colony, even in the absence of predation. The model clarifies how, even though predation may not account for all coexistence between early- and late-arriving species, it can still constitute an important force that may favor coexistence under realistic circumstances.

As argued previously, the model can be used to take account of any factor that may lead to an additional seasonal mortality of breeding individuals. One of these factors may be parasitism. First, parasitism is often seasonal and more likely to occur on islands where bird densities can be very high. Second, many parasites can induce very strong additional mortality to their hosts (see, for example, the recent outbreak of avian cholera in Amsterdam albatrosses Diomedea amsterdamensis; Weimerskirch, 2004).

Beyond inter-species competition, several works have shown that phenology is a fundamental trait for intra-species competition (in plants, Harris, 1977; but also in mammals, Mysterud et al., 2008; and insects, Frederickson, 2006). Even though the mechanisms studied here concern inter-species competition, they can also extend to situations where intra-species competition occurs (Rowan, 1965; Ramos et al., 1997), with the latest-arriving individuals failing to obtain a nest. Indeed, the date at which individuals arrive at their breeding localities can represent a heritable trait in some bird species (Brown and Brown, 2000; Møller, 2001; but see Potti, 1998). In this case, the argument that early-arriving species suffer higher mortality would be enhanced by the fact that, within a given species, arriving earlier than the optimal date of arrival (without predation) is costly (either in terms of parental or of chick mortality).

\section{Acknowledgments}

This work was supported by IPEV ("Popchat" n²79) and the "Environment \& Sustainability" Department of CNRS (“'Zone Atelier de Recherche sur 1'Environnement Antarctique et 
Subantarctique”). This work was also part of JB's postdoctoral contract at the Instituto do Mar (FCT grants SFRH/BPD/20291/2004 and SFRH/BPD/36425/2007). We thank Sébastien

Devillard, Micheline Guiserix, Frank Sauvage and two anonymous referees for helpful comments on an earlier version of the manuscript.

\section{References}

Abrams, P.A., 1999. Is predator mediated coexistence possible in unstable systems? Ecology $80,608-621$.

Armstrong, R.A., 1979. Prey species replacement along a gradient of nutrient enrichment: a graphical approach. Ecology 60, 76-84.

Atkinson, I.A.E., 1985. The spread of commensal species of Rattus rattus to oceanic islands and their effects on islands avifaunas. In: Moors, P.J. (Ed.), Conservation of Island Birds. Technical Publication No. 3. ICBP, Cambridge, UK, pp. 35-81.

Barba, E., Gil-Delgado, J.A., Monrós, J.S., 1995. The cost of being late: consequences of delaying great tit Parus major first clutches. J. Anim. Ecol. 64, 642-651.

Blackburn, T.M., Cassey, P., Duncan, R.P., Evans, K.L., Gaston, K.J., 2004. Avian Extinction and Mammalian Introductions on Oceanic Islands. Science 305 (5692), 1955-1958.

Both, C., Visser, M.E., 2001. Adjustment to climate change is constrained by arrival date in a long distance migrant bird. Nature 411, 296-298.

Bried, J., Bourgeois, K., 2005. Which future for Bulwer's petrel in the Azores? Airo 15, special issue, 51-55. Proceedings of the First International Congress "Birds of the Atlantic”, Sociedade Portuguesa para o Estudo das Aves, São Vicente (Madeira, Portugal), 29 October-1 November 2004. 
Bried, J., Magalhães, M.C., Bolton, M., Neves, V.C., Bell E., Pereira, J.C., Aguiar, L., Monteiro, L.R., Santos, R.S., 2009. Seabird habitat restoration on Praia Islet, Azores archipelago. Ecological Rest. 27, 27-36.

Brooke, M., 2004. Albatrosses and petrels across the world. Oxford University Press, Oxford.

Brown, C.R., Brown, M.B., 2000. Weather-mediated natural selection on arrival time in cliff swallows (Pterochelidon pyrrhonota). Behav. Ecol. Sociobiol. 47, 339-345.

Candolin, U., Voigt, H.-R., 2001. Correlation between male size and territory quality: consequence of male competition or predation susceptibility? Oikos 95, 225-230.

Chase, J.M., Abrams, P.A., Grover, J.P., Diehl, S., Chesson, P, Holt, R.D., Richards, S.A., Nisbet, R.M., Case, T.J., 2002 The interaction between predation and competition: a review and synthesis. Ecol. Letters 5, 302-315.

Courchamp, F., Chapuis, J.-L., Pascal, M., 2003. Mammal invaders on islands: impact, control and control impact. Biol. Rev. 78, 347-383.

Courchamp, F. Langlais, M., Sugihara, G., 1999. Cats protecting birds: modelling the mesopredator release effect. J. Anim. Ecol. 68, 282-292

Courchamp, F., Langlais, M., Sugihara, G., 2000. Rabbits killing birds: modelling the hyperpredation process. J. Anim. Ecol. 69, 154-164.

Daan, S., Dijkstra, C., Drent, R.H., Meijer, T., 1988. Food supply, and the annual timing of avian reproduction. Proceedings of the 19th International Congress of Ornithology (Ottawa), pp. 392-407.

Deacon, G.E.R., 1977. Seasonal variations in the water temperature and salinity near South Georgia 1925-1937. Report 49. Institute of Oceanography Science, Wormley, UK.

Drent, R.H., Daan, S., 1980. The prudent parent: energetic adjustment in avian breeding. Ardea 68, 225-252. 
Erikstad, K.E., Fauchald, P., Tveraa, T., Steen, H., 1998. On the cost of reproduction in longlived birds: the influence of environmental variability. Ecology 79, 1781-1788.

Frederickson, M.E., 2006. The reproductive phenology of an Amazonian ant species reflects the seasonal avaibility of its nest sites. Oecologia 149, 418-427.

Gaucel, S., Langlais, M., Pontier, D., 2005. Invading introduced species in insular heterogeneous environments. Ecol. Model. 18, 62-75.

Gaucel, S., Pontier, D., 2005. How predator food preference can change the destinity of native prey in predator-prey systems. Biol. Inv. 7, 807-816.

Gendron, R.P., 1987. Models and mechanisms of frequency-dependent predation. Am. Nat. $130,603-23$.

Greenwood, P.J., Harvey, P.H. 1982. The natal and breeding dispersal of birds. Ann. Rev. Ecol. Syst. 13, 1-21.

Harris, G.A., 1977. Root phenology as a factor of competition among grass seedlings. J. Range Management 30, 172-177.

Holt, R.D., Lawton, J.H., 1994. The ecological consequences of shared natural enemies. Ann. Rev. Ecol. Syst. 25, 495-520.

Huntly, N., 1991. Herbivores and the dynamics of communities and ecosystems. Annu. Rev. Ecol. Syst. 22, 477-503

Inchausti, P., Guinet, C., Koudil, M., Durbec, J.-P., Barbraud, C., Weimerskirch, H., Cherel, Y., Jouventin, P., 2003. Inter-annual variability in the breeding performance of seabirds in relation to oceanographic anomalies that affect the Crozet and the Kerguelen sectors of the Southern ocean. J. Avian Biol. 34, 170-176.

Jeffries, M.J., Lawton, J.H., 1984. Enemy free space and the structure of ecological communities. Biol. J. Linn. Soc. 23, 269-286. 
Johnstone, G.W., 1985. Threats to birds on subantarctic islands. In: Moors, P.J. (Ed.), Conservation of Island Birds. ICBP Technical Publication 3, 101-121.

Kokko, H., 1999. Competition for early arrival in migratory birds. J. Anim. Ecol. 68, 940-950. Lack, D., 1968. Ecological adaptations for breeding in birds. Methuen, London.

Le Corre, M., 2001. Breeding seasons of seabirds at Europa Island (southern Mozambique Channel) in relation to seasonal changes in the marine environment. J. Zool. Lond. 254, $239-249$.

Lehikoinen, E, Sparks, T.H, Žalakevičius, M., 2004. Arrival and departure dates. Adv. Ecol. Res. 35, 1-31.

Leibold, M.A., 1996. A graphical model of keystone predators in food webs: trophic regulation of abundance, incidence, and diversity patterns in communities. Am. Nat. 147, 784-812.

Møller, A.P., 2001. Heritability of arrival date in a migratory bird. Proc. R. Soc. Lond. B 268, 203-206.

Murray, J.D., 2003. Mathematical Biology, I, An introduction. Springer Verlag, Berlin. $3^{\text {rd }}$ edition.

Mysterud, A., Bonenfant, C., Loe, L.E., Langvatn, R., Yoccoz, N.G., Stenseth, N.C., 2008. The timing of male reproductive effort relative to female ovulation in a capital breeder. J. Anim. Ecol. 77, 469-477.

Nelson, J.B., 1980. Seabirds. Their biology and ecology. Hamlyn, London.

Nogales, M., Medina, F.M., 2009. Trophic ecology of feral cats (Felis silvestris f. catus) in the main environments of an oceanic archipelago (Canary Islands): an updated approach. Mamm. Biol. 74, 169-181. 
Ollason, J.C., Dunnet, G.M., 1988. Variation in breeding success in fulmars. In: CluttonBrock, T.H. (Ed.), Reproductive success. University of Chicago Press, Chicago, pp. 263278.

Palomares, E., Caro, T.M., 1999. Interspecific killing among mammalian carnivores. Am. Nat. $153,492-508$

Pontier, D., Fouchet, D., Bried, J., Bahi-Jaber, N., 2008. Limited nest site availability helps seabirds to survive cat predation on islands. Ecol. Model. 214, 316-324.

Pontier, D., Say, L., Debias, F., Bried, J., Thioulouse, J., Micol, T., Natoli, E., 2002. The diet of feral cats (Felis catus L.) at five sites on the Grande Terre, Kerguelen archipelago. Polar Biol. 25, 833-837.

Potti, J., 1998. Arrival time from spring migration in male pied flycatchers: individual consistency and familial resemblance. Condor 100, 702-708.

Pulliam, H.R., Danielson, B.J., 1991. Sources, sinks and habitat selection: a landscape perspective on population dynamics. Am. Nat. 137, suppl., 51-66.

Quintana, F., Yorio, P., 1998. Competition for nest sites between kelp gulls (Larus dominicanus) and terns (Sterna maxima and S. eurygnatha) in Patagonia. Auk 115, 10681071.

Ramos, J.A., Monteiro, L.R., Sola, E., Moniz, Z., 1997. Characteristics and competition for nest cavities in burrowing Procellariiformes. Condor 99, 634-641.

Roughgarden, J., Feldman, M., 1975. Species packing and predation pressure. Ecology 56, $489-492$.

Rowan, M.K., 1965. Regulation of sea-bird numbers. Ibis 107, 54-59.

Sandvik, H., Erikstad, K.E., 2008. Seabird life histories and climatic fluctuations: a phylogenetic-comparative time series analysis of North Atlantic seabirds. Ecography 31, $73-83$. 
Schreiber, E.A., Burger, J. (Eds.), 2002. Biology of Marine Birds. CRC Press, Boca Raton.

Sydeman, W.J., Eddy, J.O., 1995. Repeatability in egg-laying date and its relationship to individual quality for common murres. Condor 97, 1048-1052.

Veitch, C.R., 1985. Methods of eradicating feral cats from offshore islands in New Zealand. In: Moors, P.J. (Ed.), Conservation of Island Birds. ICBP Technical Publication 3, 125 141.

Waluda, C., Trathan, P., Rodhouse, P., 1999. Influence of oceanographic variability on recruitment in the Ilex argentines Cephalopoda: Ommastrephidae fishery in the South Atlantic. Mar. Ecol. Progr. Ser. 183, 159-167.

Wang, G.Y., Greenfield, M.D., Shelly, T.E., 1990. Inter-male competition for high-quality host-plants: The evolution of protandry in a territorial grasshopper. Behav. Ecol. Sociobiol. 27, 191-198.

Warham, J., 1990. The Petrels. Their Ecology and Breeding Systems. Academic Press, London.

Weimerskirch, H., 2002. Seabird demography and its relationships with the marine environment. In: Schreiber, E.A., Burger, J. (Eds.), Biology of Marine Birds. CRC Press, Boca Raton, pp. 115-135.

Weimerskirch, H., 2004. Diseases threaten Southern Ocean albatrosses. Polar Biol. 27, 374379.

Zhang, J., Fan, M., Kuang, Y., 2006. Rabbits killing birds revisited. Math. Biosci. 203, 100123. 


\section{Figure captions}

Figure 1. Schematic life cycle of seabirds, where $B_{i}$ is the number of immature birds, $B_{m}$ the number of socially mature birds, $B_{p}$ the number of prospectors and $B_{n}$ the number of occupied nests.

Figure 2. Seasonal variations in seabird behavior and predation pressures.

Figure 3. Competition between early and late breeders in the absence of predation. In this case, early breeders always outcompete late breeders. Results are shown using the basic values of the model parameters and starting with a 50-50 ratio between early and late breeders.

Figure 4. Typical evolution of competition between early (solid line) and late (dotted line) breeders when predation occurs, with examples in which (a) early breeders maintain stable numbers and late breeders go extinct $(\rho=0.5)$; (b) early breeders go extinct and late breeders thrive ( $\rho=1.5)$; (c) the two species go extinct $(\rho=3)$ and (d) the two species coexist, at least temporarily $(\rho=1)$. In all cases, $\varepsilon=0.1$, and the other parameters are set to their basic values.

Figure 5. Impact of the model parameters on the regime under which the system falls (dark grey: 'early breeders'; black: 'coexistence'; light grey: 'late breeders'; white: 'extinction' regime). The predation pressure $(\rho)$ represents the mortality rate of breeding birds during the phase of intense predation (y-axis). On the x-axis: (a) Effect of the relative 
predation pressures between the intense and weak predation phases $(\varepsilon)$; (b) effect of the time elapsed between the arrival on land of early breeders and that of late breeders $\left(\Delta_{B}\right)$ and (c) effect of the time lag between the arrival on land of the late breeders and the end of the intense predation phase. The values of the non-variable parameters are selected to be equal to their basic value. In (b-c), we select $\varepsilon=0.1$. 


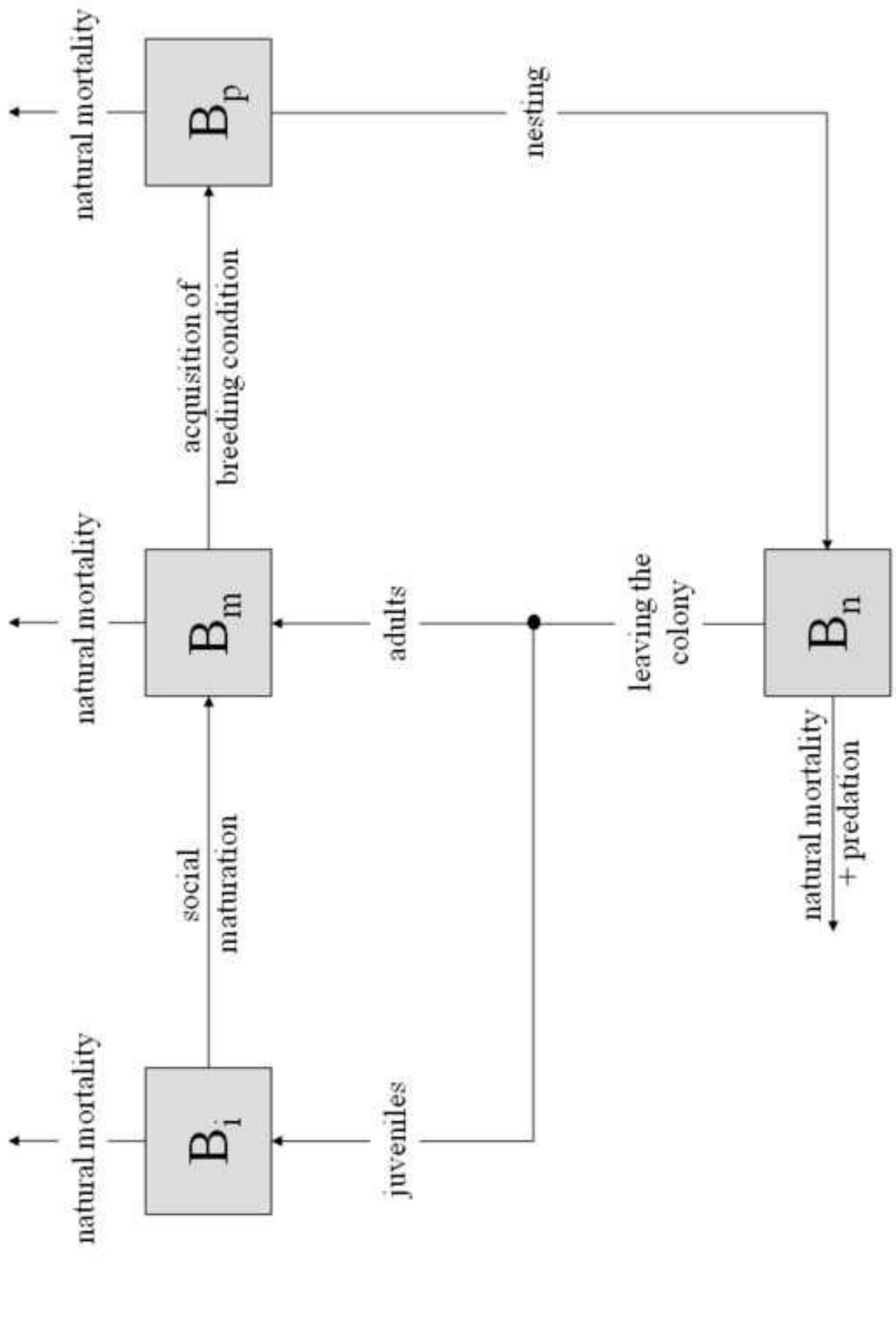




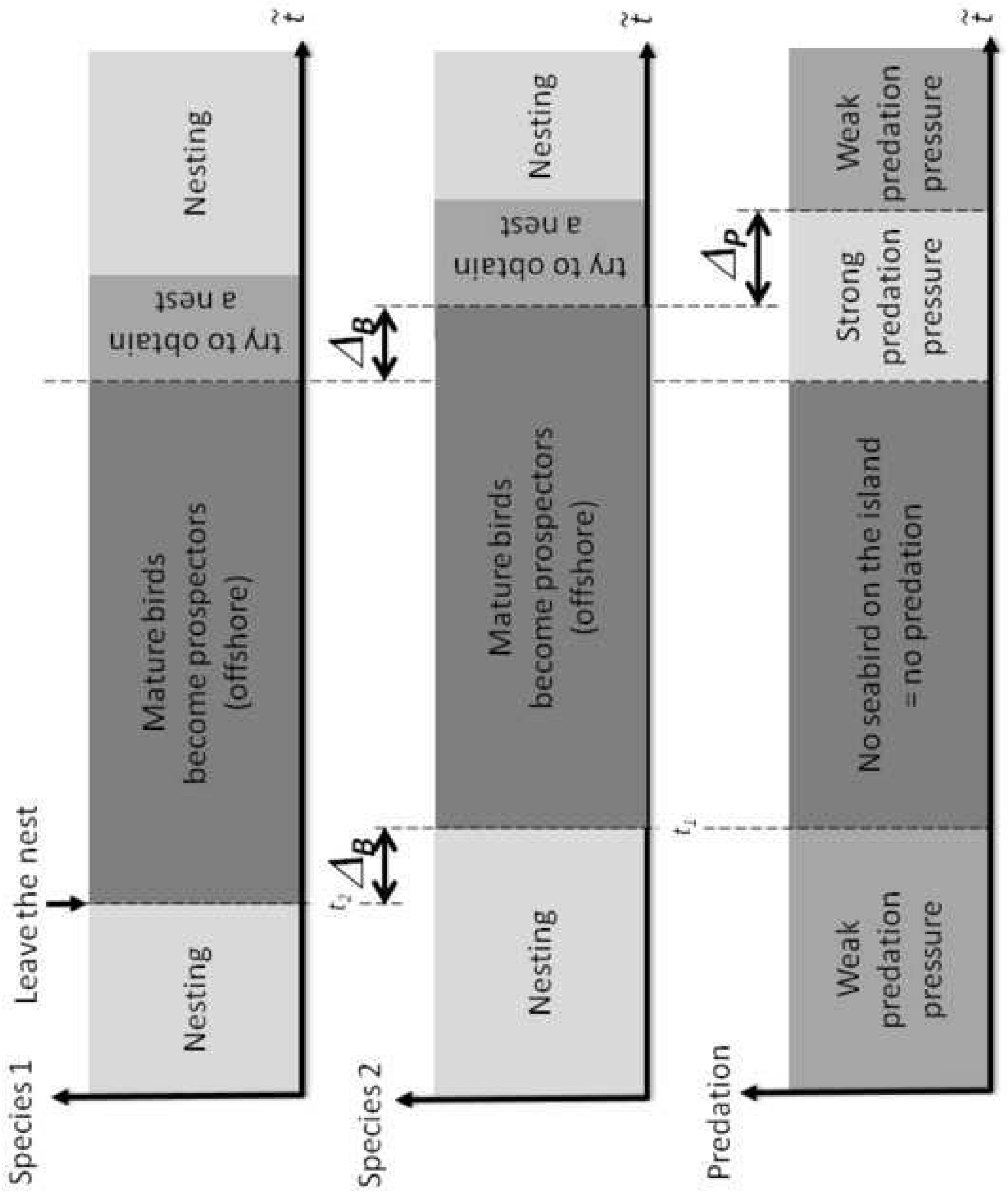

음 


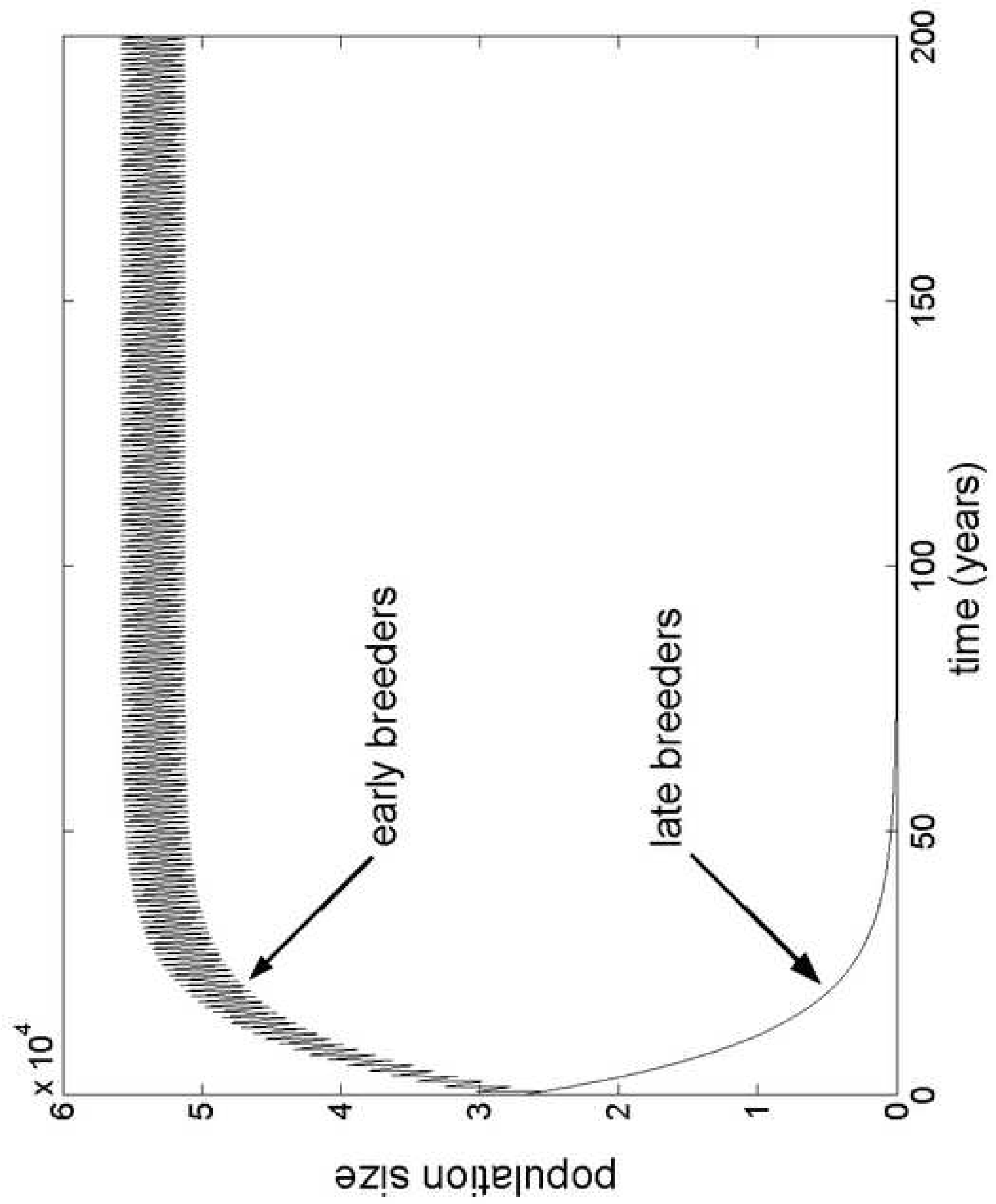



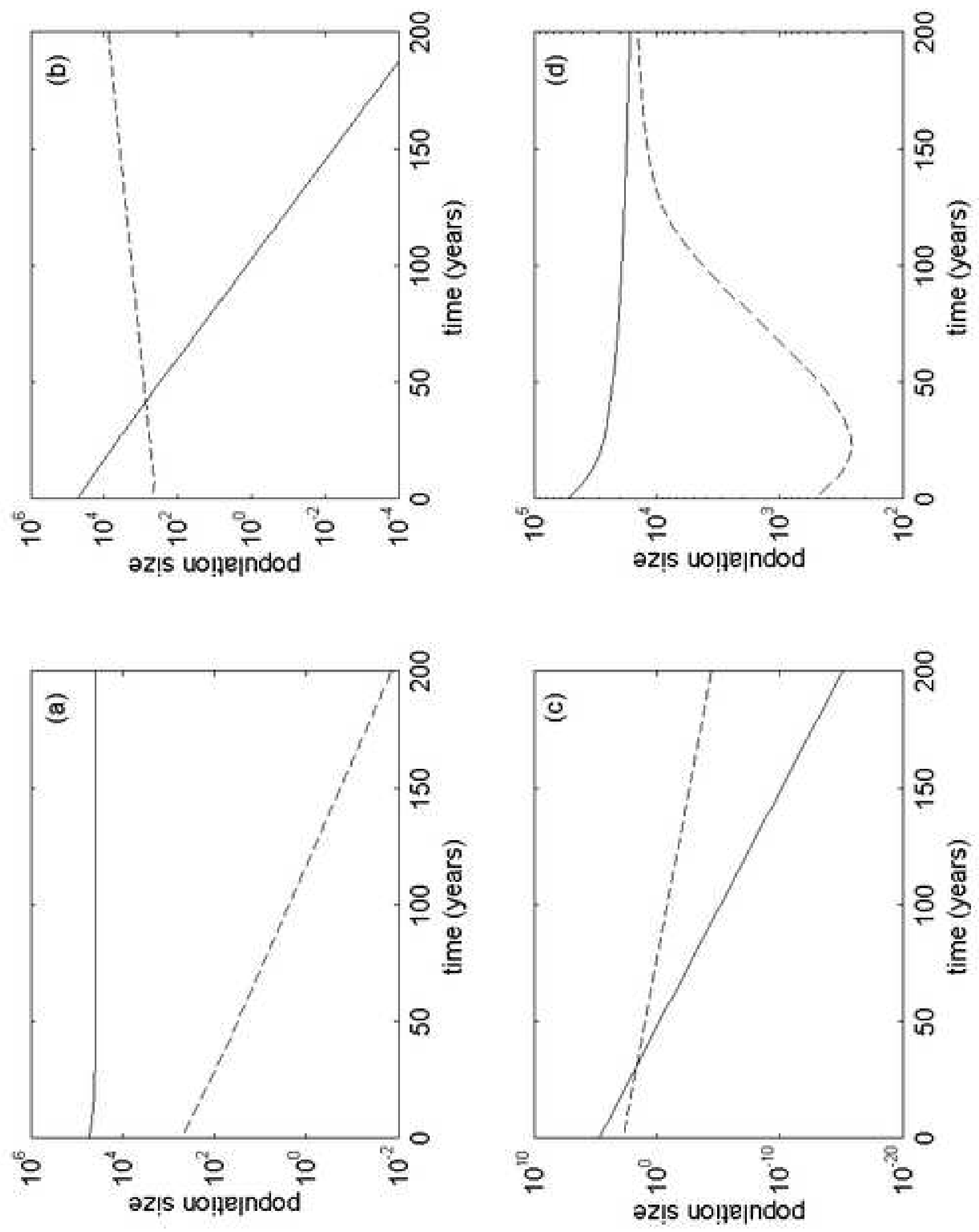

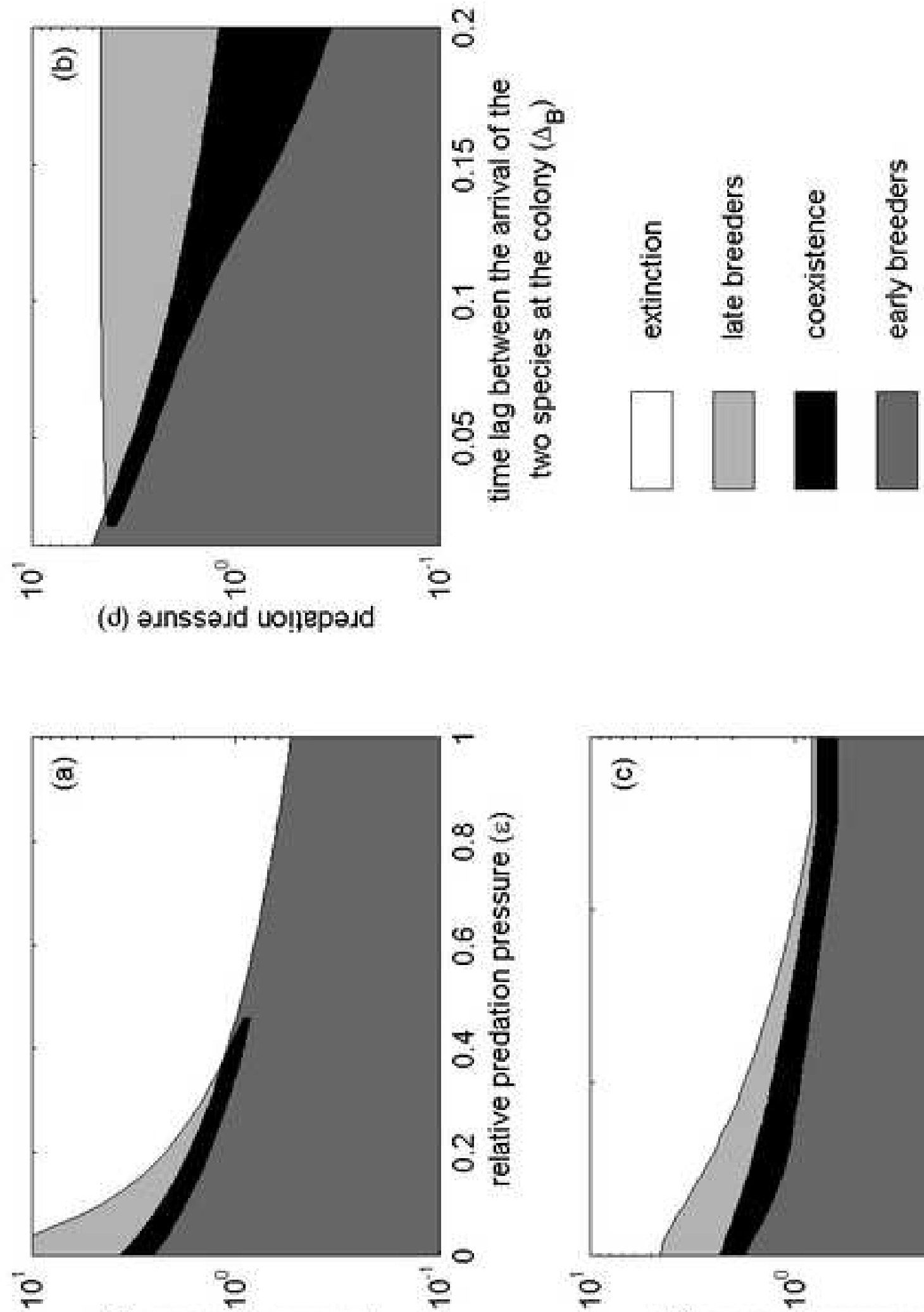

(d) əunssajd uoṇepedd

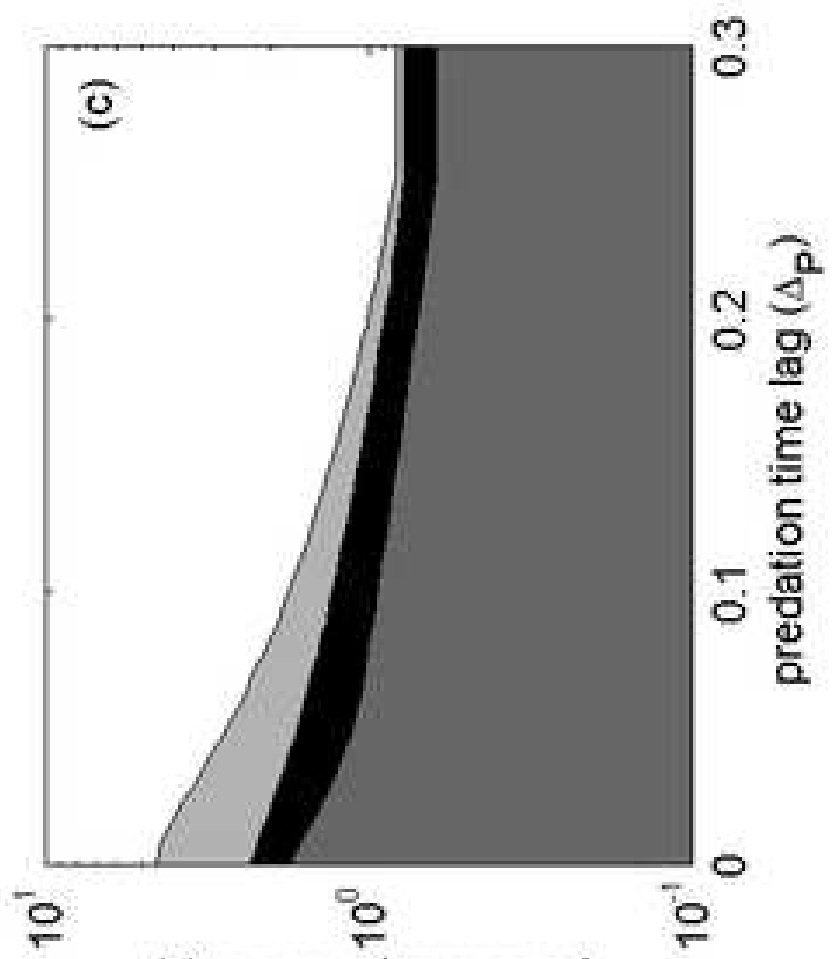

(d) a.nssajd uọ̣epaıd 